\title{
REQUISITOS ERGONÔMICOS PARA O VESTUÁRIO INFANTIL
}

\section{ERGONOMIC REQUIREMENTS FOR CHILDREN'S CLOTHING}

\author{
Tatiana Castro Longhi ${ }^{1}$, Bach. \\ Rosielli de Sá e Silva ${ }^{2}$, Bach. \\ Flávio Anthero Nunes Vianna dos $\operatorname{Santos}^{3}$ (Dr.) \\ Milton José Cinelli ${ }^{4}$ (Dr.) \\ (1) UDESC \\ e-mail: dilonghi@gmail.com \\ (2)UDESC \\ e-mail: rosiellisa@gmail.com \\ (3) UDESC \\ e-mail: flavioanvs@ hotmail.com \\ (4) UDESC \\ e-mail: milton.cinelli@udesc.br
}

\begin{abstract}
Palavras-chave em português (criança, vestuário, ergonomia)
O artigo apresenta requisitos ergonômicos para o vestuário infantil, com foco no público até os sete anos de idade. Para que esses requisitos possam ser assimilados no planejamento de produto, utiliza-se como base os Parâmetros Ergonômicos para Confecção de Rosa (2011) e as recomendações da Norma Regulamentadora NBR 16365:2015.

Key-words in English (children, clothing, ergonomics)

This article presents ergonomic requirements for children's clothing focusing on public until seven years old. In order to adopt these recommendations on product management are used as basis the Ergonomics Parameters for Clothing of Rosa (2011) and the recommendations of the Regulatory Standard NBR 16365:2015.
\end{abstract}

\section{Introdução}

A infância é o período no qual as experimentações estão em evidência. $\mathrm{O}$ desenvolvimento saudável das crianças vem a partir de sua interação com o ambiente, por meio de brincadeiras e descobertas.

Assim, com o tempo os limites e critérios do que pode ou não fazer são apreendidos, compondo os fundamentos para a construção de sua personalidade.

Desse modo, nos primeiros anos de vida, de 0 a 3 anos, a criança absorve as informações no modo perceptivo, por meio da visão e no modo sensorial, por meio do toque. (MONTIGNEAUX, 2003 apud VOIGT, 2007). Durante essa fase de descoberta dos movimentos e capacidades, as crianças se expõem a perigos, como se enroscar em cordões ou se engasgar com pequenos objetos, e o vestuário também precisa oferecer segurança.

É comum crianças mais novas colocarem objetos na boca e os elementos do vestuário infantil devem resistir a esse teste. A escolha dos tecidos também é importante, pois conforme a composição eles podem ser inflamáveis em situação de fogo. É preciso verificar, através de testes, se os elementos que compõem o vestuário não contêm substâncias nocivas, para que não agridam a saúde da criança. (SEBRAE/SIS, 2014).

Segundo a ABNT (2015) não há dados nacionais específicos sobre acidentes com vestuário, mas grande parte ocorre durante o lazer, em parquinhos. No caso dos bebês, a sufocação é a principal causa de mortes até um ano de idade. Nos Estados Unidos, 
conforme dados da Consumer Product Safety Commission (CPSC), de 1985 a 2011, foram 110 casos de acidentes com crianças envolvendo vestuário, com oito mortes. Diante disso, entre 2012 e 2013, a CPSC anunciou mais de 760 lembretes de roupas e acessórios infantis, relativos a itens como cordões longos que poderiam oferecer risco de estrangulamento, requisitos de flamabilidade, entre outros.

De acordo com dados da Associação Brasileira da Indústria Têxtil (ABIT), o segmento de vestuário infantil e de bebê movimenta cerca de $\mathrm{R} \$ 50$ bilhões ao ano. Destes, $60,1 \%$ compõem-se de roupas casuais, $14 \%$ de roupas esportivas, $9,9 \%$ roupas de inverno e 9,9\% outras (SEBRAE/SIS, 2014). Para que esse mercado em expansão atenda satisfatoriamente o seu público, destaca-se a importância de uma série de cuidados no planejamento do produto, uma vez que a qualidade é, nesse segmento, uma questão de segurança.

Além desses fatores, deve-se pensar também sobre a ergonomia da roupa, no sentido de oferecer satisfação, segurança e praticidade à criança e seus responsáveis.

Assim, o artigo apresenta os requisitos ergonômicos para o vestuário infantil, a fim de que esse setor contemple durante o projeto fatores inerentes ao desenvolvimento da criança e sua adequação com o meio no qual interage.

\section{Procedimentos Metodológicos}

Para que fosse possível obter os Requisitos Ergonômicos para o Vestuário Infantil, utilizou-se como base os Parâmetros Ergonômicos para Confecção de Rosa (2011), os quais estabelecem critérios concernentes aos Fatores Humanos no Vestuário. Além disso, foram utilizadas as recomendações da Norma Regulamentadora NBR 16365:2015, que prevê a segurança nas roupas infantis para crianças menores $(0$ a 7 anos completos) e maiores (de 7 a 14 anos completos). Sendo que o escopo da pesquisa compreende a faixa etária das crianças menores, que tem maior risco de acidentes em vista dos elementos do vestuário (ABNT, 2015).

Assim, tendo em vista esses direcionamentos e também as fases do desenvolvimento da criança, foram estipulados os Requisitos Ergonômicos para o Vestuário Infantil até a fase da segunda infância, que segundo Manning (1977), é o período dos seis aos doze anos, mas como essa pesquisa aborda o público de crianças menores, as recomendações seguem até os sete anos de idade.

\section{Fases do Desenvolvimento Infantil}

O desenvolvimento infantil é pautado pela sua evolução nos segmentos físico, cognitivo e social da criança (Piaget apud Mussen, Conger e Kagan, 1977). Nesse sentido, características do meio no qual ela convive e os agentes de interação, como pessoas e objetos contribuem na construção de sua personalidade, aprendizado e habilidades motoras, entre outros fatores que irão interferir no seu crescimento.

Assim, para cada fase existem características próprias pelas quais a criança passa durante seu processo evolutivo. Ainda que exista um padrão comum de desenvolvimento, cada criança obedece a seu ritmo individual. Para Manning (1977), essas etapas podem ser divididas entre os anos da primeira infância, os pré-escolares e os da segunda infância. Posteriormente ocorre a fase da adolescência na transição dessa criança até se tornar adulta.

A primeira infância compreende os dois primeiros anos de vida e é o período de crescimento mais rápido. Quanto ao desenvolvimento motor, as habilidades irão depender da maturidade do sistema nervoso central, e do tipo de ambiente e estado de saúde no qual a criança se encontra. Pode variar conforme dois padrões. O primeiro refere-se à sequência cefalocaudal, a qual inicia-se perto do cérebro e prossegue pelo resto do corpo (MANNING, 1977). Por esse processo as crianças aprendem a erguer a cabeça antes de estender os braços, e usam os braços e mãos antes de poderem usar as pernas e pés.

No segundo padrão, proximodistal (do próximo para o distante), o desenvolvimento segue da medula espinhal para fora. Assim, os bebês controlam primeiramente o tronco, para depois controlarem braços e pernas, primeiro os membros superiores para depois inferiores, sendo que cada habilidade irá depender do domínio da anterior. 
Nos anos pré-escolares, que ocorre entre os dois e cinco anos de idade, as crianças passam para o período denominado pré-escolar. Nessa fase o desenvolvimento cognitivo e social entra em evidência e irá variar conforme a criança tenha consciência de si mesma.

O crescimento físico é mais lento e o formato do corpo já sofre modificações. Os sistemas muscular, esquelético e nervoso amadurecem e nesse processo a ossificação é intensificada.

Quanto ao desenvolvimento motor, esse é aprimorado e nessa etapa a criança é capaz de executar ações mais complexas, como correr, pular, e subir com facilidade. Aos cinco anos o senso de equilíbrio também já está desenvolvido o que lhe permite maior destreza nas tarefas (MUSSEN, CONGER e KAGAN, 1977); (FORTKAMP e RAUPP, 1989).

Nessa etapa o desenvolvimento perceptivo irá evoluir com o passar da idade, e as crianças aprendem a distinguir entre objetos e reconhecer melhor o ambiente conforme suas experiências. A percepção irá realizar a organização das informações e classificar em categorias que façam sentido à criança.

A segunda infância envolve o período dos seis aos doze anos de idade, no qual o crescimento físico é constante e gradual, e o desenvolvimento do cérebro está quase completo. O desenvolvimento motor está em plena expansão e as crianças realizam tarefas ainda mais complexas como praticar esportes, e outras habilidades com maior nível de dificuldade.

Crianças nessa fase, no entanto, tendem a apresentar maior número de acidentes, uma vez que essa fase é extremamente ativa e curiosa. Deve-se atentar, portanto, com relação ao ambiente e aos fatores que possam ocasionar essas situações (MANNING, 1977; VIGOSTSKII, LURIA e LEONTIEV, 1988).

No que concerne aos estágios psicanalíticos do desenvolvimento, a teoria de Freud envolve as zonas corporais mais focadas pelas crianças em cada fase. Assim, durante a infância, o primeiro ano de vida é caracterizado como estágio oral, uma vez que a criança apresenta prazer com experiências que compreendem a região da boca.

No segundo e terceiro anos de vida, ocorre o estágio anal, no qual a região do reto é estimulada em consequência das atividades como banho e tato que estimulam a área. Nos anos pré-escolares, os genitais são evidenciados e esse é o estágio fálico.

Esses estágios para Freud (apud MUSSEN, KONGER e KAGAN, 1977), contribuem para o desenvolvimento emocional da criança e experiências ambientais desfavoráveis e situações do meio poderiam interferir nesse processo de amadurecimento emocional.

Para Montigneaux (2003 apud Voigt, 2007) o desenvolvimento infantil é dividido em três períodos, como exposto na tabela 1 . O primeiro, compreendido até os dois anos de idade, é conhecido como "sensório-motor" (PIAGET, 1966 apud VOIGT, 2007, p. 51), pois o desenvolvimento do bebê nesta fase está ligado às atividades que compreendem esses setores. É um período marcado pela experimentação e a sua interação com objetos, ao passo que o bebê desvia sua atenção do interior para os objetos no exterior.

\begin{tabular}{|c|c|c|c|}
\hline Idade & $\begin{array}{l}\text { Desenvolvimento } \\
\text { Cognitivo }\end{array}$ & $\begin{array}{l}\text { Desenvolvi- } \\
\text { mento } \\
\text { Psicológico }\end{array}$ & Socialização \\
\hline \multirow{5}{*}{$\begin{array}{l}0 \\
\text { a } \\
2-3 \\
\text { anos }\end{array}$} & $\begin{array}{l}\text { Pensamento e } \\
\text { ação estão } \\
\text { próximos. }\end{array}$ & $\begin{array}{l}\text { Relação } \\
\text { simbólica com } \\
\text { a mãe. }\end{array}$ & $\begin{array}{l}\text { A criança se } \\
\text { isola em si } \\
\text { Mesma. }\end{array}$ \\
\hline & $\begin{array}{l}\text { Capacidade } \\
\text { limitada de } \\
\text { Raciocínio. }\end{array}$ & $\begin{array}{l}\text { Processo de } \\
\text { individualizaçã } \\
\text { o em relação à } \\
\text { mãe } \\
\text { (consciência } \\
\text { da sua própria } \\
\text { existência). }\end{array}$ & $\begin{array}{l}\text { Dificuldade de } \\
\text { comunicação. }\end{array}$ \\
\hline & $\begin{array}{l}\text { “Inteligência da } \\
\text { ação". }\end{array}$ & \multirow[t]{3}{*}{$\begin{array}{l}\text { A criança } \\
\text { diferencia o } \\
\text { mundo interior } \\
\text { (o eu) do } \\
\text { exterior (o } \\
\text { não-eu). }\end{array}$} & $\begin{array}{l}\text { Autonomia } \\
\text { pelo controle } \\
\text { do corpo } \\
\text { (controle da } \\
\text { evacuação) ou } \\
\text { oposição } \\
\text { (não.) }\end{array}$ \\
\hline & $\begin{array}{l}\text { Trata as } \\
\text { informações no } \\
\text { modo perceptivo } \\
\text { (ver) e sensorial } \\
\text { (tocar). }\end{array}$ & & \multirow[t]{2}{*}{$\begin{array}{l}\text { Os pais } \\
\text { constituem o } \\
\text { principal } \\
\text { agente da } \\
\text { socialização }\end{array}$} \\
\hline & $\begin{array}{l}\text { Início do acesso à } \\
\text { representação } \\
\text { simbólica dos } \\
\text { objetos. }\end{array}$ & & \\
\hline
\end{tabular}

Tabela 1: Características das crianças, com idade entre o nascimento e os dois anos.

Fonte: Montigneaux, 2003 apud Voigt, 2007. 
O segundo período, é o "pré-operacional", como mostra a tabela 2. Para Piaget (apud Voigt, 2007), é a fase na qual a criança desenvolve sua personalidade e autonomia. Este período é caracterizado pelo universo simbólico, no qual a criança intensifica sua capacidade de abstração e subjetividade. Seu raciocínio é analógico, comparando o que descobre com o aquilo que conhece.

\begin{tabular}{|c|c|c|c|}
\hline & $\begin{array}{l}\text { Desenvolvimen } \\
\text { to } \\
\text { Cognitivo }\end{array}$ & $\begin{array}{l}\text { Desenvolvi- } \\
\text { mento } \\
\text { Psicológico }\end{array}$ & Socialização \\
\hline \multirow[t]{6}{*}{$\begin{array}{c}2-3 \\
\text { a } \\
07 \\
\text { ano } \\
\text { s }\end{array}$} & $\begin{array}{l}\text { As ações são } \\
\text { interiorizadas. }\end{array}$ & $\begin{array}{l}\text { Construção de } \\
\text { uma imagem } \\
\text { mental da mãe. }\end{array}$ & $\begin{array}{l}\text { Início da } \\
\text { atividade } \\
\text { social por } \\
\text { imitação } \\
\text { dos adultos. }\end{array}$ \\
\hline & $\begin{array}{l}\text { A criança é } \\
\text { capaz de se } \\
\text { projetar no } \\
\text { tempo e no } \\
\text { Espaço. }\end{array}$ & $\begin{array}{l}\text { Atividade } \\
\text { fantasmagóri-ca } \\
\text { (sonho, } \\
\text { imaginário e } \\
\text { realidade se } \\
\text { misturam). }\end{array}$ & $\begin{array}{l}\text { Brinca com } \\
\text { outras } \\
\text { crianças } \\
\text { (atividades } \\
\text { lúdicas mais } \\
\text { cooperativas). }\end{array}$ \\
\hline & $\begin{array}{l}\text { Desenvolviment } \\
\text { o da função } \\
\text { simbólica } \\
\text { (representar) } \\
\text { mentalmente os } \\
\text { objetos } \\
\text { concretos. }\end{array}$ & \multirow[t]{4}{*}{$\begin{array}{l}\text { Desenvolviment } \\
\text { o da sua } \\
\text { personalidade e } \\
\text { da identidade } \\
\text { sexual. }\end{array}$} & \multirow[t]{4}{*}{$\begin{array}{l}\text { Abertura } \\
\text { social da } \\
\text { criança } \\
\text { dependente } \\
\text { dos } \\
\text { pais ainda. }\end{array}$} \\
\hline & $\begin{array}{l}\text { Desenvolviment } \\
\text { o da linguagem. }\end{array}$ & & \\
\hline & $\begin{array}{l}\text { Raciocínio } \\
\text { apoiado na } \\
\text { percepção } \\
\text { das coisas. }\end{array}$ & & \\
\hline & $\begin{array}{l}\text { Representação } \\
\text { do mundo } \\
\text { fortemente } \\
\text { personalizada. }\end{array}$ & & \\
\hline
\end{tabular}

Tabela 2: Características das crianças, entre dois e sete anos de idade.

Fonte: Montigneaux, 2003 apud Voigt, 2007.

Assim, a interação da criança com o vestuário e o ambiente exterior será pautada pelo seu grau de desenvolvimento cognitivo, psicológico e social. Desse modo, pequenos adereços e detalhes do vestuário podem tornar-se um risco para a criança uma vez que ela está em um período de experimentações. Por isso, o vestuário infantil deve levar em consideração também as normas propostas pela ABNT.

\section{Normas Técnicas para o Vestuário Infantil}

Durante o período da infância, o risco de acidentes é intensificado, uma vez que as crianças estão em fase de desenvolvimento e aprendizado. Por isso, a
ABNT (2016), prevê uma série de normas relativas à segurança e ao bem-estar infantil durante o cumprimento de suas funções. Desde normas relacionadas aos artigos de puericultura (NBR 15260:2005); segurança de mamadeiras (NBR 13793:2003) e mobiliário infantil (NBR 15860:2010); até normas que garantem a segurança de brinquedos (NBR NM 300-1:2004); roupas (NBR 16365:2015); direcionamentos antropométricos e vestibilidade (NBR 15800:2009).

As normas para vestuário infantil foram desenvolvidas a fim de prevenir acidentes e orientar a indústria quanto aos critérios necessários para a fabricação de produtos para esse nicho de mercado. Para isso, considera-se a idade da criança, o seu comportamento em função do seu estágio de desenvolvimento, as suas atividades diárias e a capacidade de se cuidarem sozinhas ou não (ABNT, 2015).

Nesse sentido, a norma NBR 16365:2015

(Segurança de roupas infantis) determina os riscos físicos em cordões fixos e ajustáveis e aviamentos em roupas infantis, divididos por duas faixas estarias: crianças menores (de 0 até 7 anos completos) e crianças maiores (de 7 anos até 14 anos completos). A partir disso, define-se uma série de requisitos de segurança, sendo alguns dos principais deles expostos no presente estudo.

Crianças mais jovens apresentam maior risco de acidentes graves em brinquedos de parquinhos, podendo resultar em mortes. Já as crianças mais velhas e adolescentes apresentam risco de enganchamento de cordões da cintura, cadarços, e bainhas inferiores em portas de veículos em movimento, que podem ocasionar ferimentos graves ou morte por arrastamento ou atropelamento. Em vista disso, a ABNT (2015) recomenda que uma avaliação de risco individual seja realizada em qualquer roupa e comprovada por meio de pesquisa, a fim de preservar a segurança do usuário.

Assim, no que tange às recomendações dessa norma, os aviamentos devem ser resistentes a quebra e ao arrancamento, principalmente no vestuário de crianças menores de 3 anos de idade. Os zíperes devem ter uma aba protetora interna que impeça que o correr do cursor prenda a pele. Os velcros devem ser evitados, mas se utilizados devem ter as pontas arredondadas e a parte áspera deve ser costurada 
com a face para cima. Puxadores de zíperes não podem ter mais que $75 \mathrm{~mm}$ de comprimento a partir do cursor e não podem ficar suspensos abaixo da borda inferior das roupas. Na imagem seguinte (figura 1), o zíper da esquerda está na posição correta, enquanto o da direita está abaixo do limite.

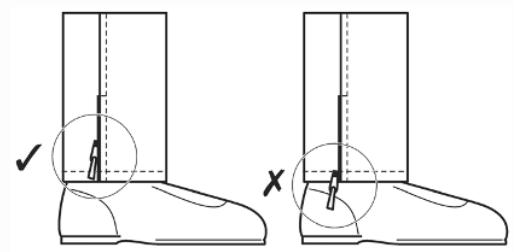

Figura 1: Localização do zíper em relação à barra da peça Fonte: ABNT, 2015

As etiquetas têxteis devem ser compostas de material macio ou fixadas por meio de estamparia. A fixação de etiquetas ou quaisquer adereços não pode ser feita com linha de monofilamento (nylon) devido à agressão que esse material pode causar ao usuário.

Os bordados, especialmente para as crianças menores de três anos de idade, devem ter forro interno, evitando atrito com a pele. As embalagens de roupas infantis devem conter informações sobre os riscos de sufocamento.

Faixas, cintos e cordões têm tamanho máximo estipulado em função da idade da criança. Roupas destinadas a crianças menores, segundo ABNT (2015), não podem conter cordões na área do capuz ou pescoço, sejam eles funcionais ou decorativos. Faixas e cordões, depois de amarrados, não podem passar do limite da roupa em comprimento.

Os cordões não podem gerar risco de enganchamento. Desse modo, cordões ajustáveis devem ser fixados à roupa em pelo menos um ponto, posicionados equidistantes dos pontos de saída. As ponteiras dos cordões devem resistir ao arrancamento, como mostra a figura 2 .

Arremate para prender o cordão

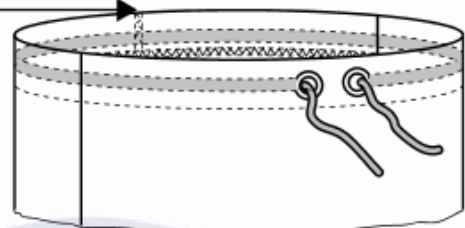

Figura 2: Exemplo de cordão ajustável com costura de arremate
Fonte: ABNT, 2015

Constituem exceções à norma as roupas utilizadas sob supervisão de adulto, tais como gravatas de uniforme escolar, roupas esportivas, trajes teatrais de uso específico, roupas de dança e trajes típicos folclóricos.

Nesse sentido, pode-se observar também algumas diferenças no que concerne as idades das crianças. No caso dos aviamentos, ainda que não contenham arestas que possam ferir, devem ser feitos de material de qualidade e precisam ser fixados de forma definitiva, evitando que crianças menores os engulam, caso os levem a boca.

Para os cordões, faixas, cintos e cadarços, os riscos referem-se ao enganchamento ou até mesmo enforcamento, independente da idade. Assim, as normas ressaltam a importância do tamanho máximo que estes podem apresentar em roupas infantis.

Por sua vez, a NBR 15800 estabelece critérios para o vestuário infantil por meio de referenciais de medidas do corpo humano e vestibilidade de roupas para bebê e infanto-juvenil.

Assim, o objetivo da norma é apresentar medidas antropométricas para tamanhos que variam desde o bebê recém-nascido (PP) até adolescentes de 14 anos (tamanho 14).

Com isso é possível desenvolver produtos que sejam compatíveis com as medidas da criança e do adolescente, a fim de que os tamanhos sejam padronizados e as peças tenham uma melhor usabilidade.

Desse modo, por meio do direcionamento proposto por essas normas, pode-se ter um referencial para que o vestuário infanto-juvenil seja

ergonomicamente adequado ao usuário.

\section{Requisitos ergonômicos no vestuário}

Do ponto de vista ergonômico, para Iida (2005), os produtos são meios que permitem ao homem executar determinadas funções. Para que a interação entre usuário e produto ocorra satisfatoriamente, três características básicas devem estar presentes qualidade técnica, estética e ergonômica. A qualidade técnica diz respeito ao funcionamento do produto, a eficiência em executar a sua função, 
manutenção, facilidade de limpeza etc. A qualidade ergonômica: garante uma boa interação entre $o$ usuário e o produto, proporcionando conforto e segurança. Finalmente, a qualidade estética é aquela que proporciona prazer ao consumidor, através da combinação de formas, cores, materiais etc

Para que o vestuário contemple os requisitos ergonômicos pertinentes a ele, é preciso que estes sejam incorporados desde a etapa projetual. Para Martins (2005) esses requisitos englobam as propriedades ergonômicas básicas - segurança, facilidade de manejo, de assimilação, de manutenção e segurança - e os índices ergonômicos físicos, psicológicos, psicofisiológicos e higiênicos. A seguir, serão apresentados alguns dos materiais e processos que possibilitam a interação entre a roupa e o usuário, tais como, tecidos, aviamentos, modelagem, acabamentos, etiquetas e manutenção.

\subsection{Tecidos}

Os tecidos têxteis são obtidos por meio do entrelaçamento de um ou mais fios, compostos de uma fibra ou da mistura de fibras. Os tecidos planos derivam do entrelaçamento dos fios do urdume e da trama, formando três ligamentos básicos de fios: tafetá, sarja e cetim.

Segundo Pezzolo (2007), a origem da fibra pode ser natural ou química. As fibras naturais dividem-se em vegetais (algodão, cânhamo, linho, juta, sisal, ráfia etc.) e animais (lãs de carneiro, coelho, lhama, alpaca e seda). As fibras químicas artificiais podem ser de matéria-prima natural vegetal, mineral ou animal e as fibras químicas sintéticas vêm do petróleo. São fibras químicas artificiais: Raion, Modal, Tencel ${ }^{\circledR}$ Liocel, amianto, entre outras; são fibras químicas sintéticas: acrílico, elastano (Lycra®), poliamida (náilon), poliéster, polipropileno, entre outras.

Do ponto de vista do usuário de artigos de vestuário, as características mais importantes dos tecidos de que são feitas as roupas são, basicamente, conforto tátil e térmico, durabilidade, caimento etc. Do ponto vista técnico, Pezzolo (2007) explica que as propriedades das fibras são as seguintes: Finura: quanto mais fina for a fibra, mais agradável ao toque será o tecido.
Elasticidade: a capacidade de a fibra voltar ao normal após alongamento.

Resistência: a capacidade de certas fibras voltarem ao seu estado inicial após serem amarrotadas.

Toque: sensação de conforto em contato com a pele. Hidrofilidade: capacidade de absorção e retenção da água que algumas fibras possuem, como as naturais. Hidrofobilidade: capacidade de absorver lentamente a água ou mesmo de repeli-la, como as sintéticas. Comportamento diante de produtos químicos: avaliação da reação da fibra quando em contato com ácidos, álcool e solventes orgânicos.

Desgaste: análise do comportamento das fibras mediante a ação de agentes mecânicos.

As malhas podem ser feitas a partir de um único fio, o que lhes confere uma elasticidade natural, mesmo que não contenham fibras elásticas como o elastano. As fibras que compõem a malha podem ser naturais, como a meia malha de algodão, comum em camisetas, ou sintéticas, como a malha de poliéster usada em artigos esportivos.

\subsection{Aviamentos}

Os aviamentos são materiais que compõem a roupa juntamente com o tecido, possibilitando a sua utilização ou somente com função decorativa. Assim, Treptow (2003) classifica os aviamentos quanto à função e quanto à visibilidade.

Componentes, são aqueles sem os quais o vestuário não pode ser utilizado, tais como zíperes, botões de abertura, etiquetas informativas etc. Decorativos, são os aviamentos sem uma função prática além da estética, como franjas, debruns, etiquetas decorativas etc. Existem aviamentos funcionais que podem ou não ser aparentes, como os elásticos, por exemplo, porém os decorativos estão sempre visíveis.

\subsection{Modelagem}

A modelagem do vestuário consiste na construção de um diagrama do corpo humano, baseado nas medidas relativas aos perímetros e as alturas do corpo, construído dentro das especificações úteis ao vestuário. A partir do diagrama, é possível desenvolver os moldes que serão utilizados no corte dos tecidos nos formatos desejados para compor as peças de roupas. Como as medidas que geram os diagramas são oriundas de seres humanos, $o$ diagrama bidimensional é feito de forma a acomodar 
a forma tridimensional do corpo. Dessa maneira, uma modelagem confortável, deve considerar os movimentos de flexão, extensão, adução e abdução, rotação e inclinação e as limitações do usuário, em atividade ou repouso. Rosa (2011) considera que, as funções anatômicas, fisiológicas e psicológicas, devem ser consideradas na modelagem. Dessa forma, o desenvolvimento do vestuário ergonômico, deve observar a morfologia do corpo humano, no que tange à postura estática e em movimento.

Outros aspectos que determinam a modelagem são: o tecido no qual a peça será produzida, o gênero (masculino ou feminino) dentro de um segmento, a função e o estilo (social, esportivo etc).

\subsection{Acabamentos}

Os acabamentos são as finalizações realizadas no vestuário após a sua montagem. Assim, existem acabamentos aparentes, como bainhas e pespontos, e acabamentos internos, como a costura feita em máquina de overlock nas bordas internas das roupas, ou a mesma costura feita com viés, que resulta em um acabamento mais sofisticado e durável.

\subsection{Etiqueta}

A etiqueta aqui abordada refere-se à etiqueta interna do vestuário e não diz respeito à marca da empresa que a comercializa. Essa etiqueta é obrigatória no Brasil em todo o produto têxtil de origem nacional ou estrangeiro e deve ser costurada simultaneamente a costura da roupa ou fixada no próprio tecido internamente através de estamparia. Segundo Rosa (2002) ela existe para fornecer seis informações obrigatórias sobre o produto têxtil: nome da empresa, CNPJ, país de origem, composição das fibras, cuidados e conservação do produto e tamanho do produto.

\subsection{Manutenção}

A manutenção do vestuário é à forma como o usuário trata a peça de roupa após o seu uso, como lavagem (uso de produtos químicos), secagem, passadoria (temperatura do ferro) e acondicionamento. Essa manutenção deve ser baseada nas informações fornecidas pelo fabricante do produto, constantes na etiqueta afixada na peça, relacionadas à matéria-prima que a compõe. $\mathrm{O}$ desempenho e a durabilidade da roupa estão diretamente ligados à sua conservação por parte do usuário, embora a qualidade do material seja fundamental para determinar a sua vida útil em bom estado.

\section{Os parâmetros ergonômicos para confecção com base no Método Aplicável ao Vestuário}

Para idealizar um projeto de vestuário de forma que atenda aos requisitos ergonômicos e necessidades do usuário, deve-se atentar para fatores e funções que proporcionem praticidade, conforto e segurança durante a utilização do produto (ROSA, 2011).

Assim, com base nos estudos de Iida (2005) e Martins (2005), Rosa (2011) elaborou as categorias para o Método Aplicável ao Vestuário. O qual consiste em um conjunto de parâmetros que devem ser aferidos de forma sistemática durante o processo de fabricação do vestuário, desde a etapa da concepção até sua comercialização.

Desse modo, com base nas qualidades Técnicas, Ergonômicas e Estéticas do produto proposto por Iida (2005) e a Metodologia Oikos de Martins (2005), Rosa (2011) comparou quais seriam os critérios necessários à indústria do vestuário para que as peças tenham melhor qualidade, durabilidade e competitividade no mercado, tendo em vista a experiência do usuário com o produto, como mostra a tabela 3 .

\begin{tabular}{|c|c|c|}
\hline \multicolumn{2}{|c|}{ Estudos de lida (2005) } & Categorias do \\
\hline $\begin{array}{l}\text { Qualidade } \\
\text { Técnica }\end{array}$ & $\begin{array}{l}\text { 1) Eficiência com que o } \\
\text { produto executa a } \\
\text { função; } \\
\text { 2) Rendimento na } \\
\text { conversão de energia; } \\
\text { 3) Ausência de ruídos e } \\
\text { vibrações; } \\
\text { 4) Facilidade de } \\
\text { limpeza e manutenção. }\end{array}$ & $\begin{array}{l}\text { 1) Eficiência com } \\
\text { que o produto } \\
\text { executa a função; } \\
\text { 2) Facilidade de } \\
\text { limpeza e } \\
\text { manutenção; } \\
\text { 3)Questões } \\
\text { ecológicas; } \\
\text { 4) Facilidade } \\
\text { organização na } \\
\text { produção; } \\
\text { 5) Facilidade } \\
\text { Tecnológica; } \\
\text { 6) Sequência } \\
\text { operacional. }\end{array}$ \\
\hline $\begin{array}{l}\text { Qualidade } \\
\text { Ergonômica }\end{array}$ & $\begin{array}{l}\text { 1) Facilidade de } \\
\text { manuseio; } \\
\text { 2) Adaptação } \\
\text { antropométrica; } \\
\text { 3) Fornecimento claro } \\
\text { de informações; }\end{array}$ & $\begin{array}{l}\text { 1) Facilidade de } \\
\text { manuseio; } \\
\text { 2) Adaptação } \\
\text { antropométrica; } \\
\text { 3) Fornecimento } \\
\text { claro de }\end{array}$ \\
\hline
\end{tabular}




\begin{tabular}{|c|c|c|}
\hline & $\begin{array}{l}\text { 4) Facilidade de } \\
\text { "navegação"; } \\
\text { 5) Compatibilidade de } \\
\text { movimentos; } \\
\text { 6) Conforto e } \\
\text { Segurança. }\end{array}$ & $\begin{array}{l}\text { informações; } \\
\text { 4) Facilidades para } \\
\text { vestir e despir; } \\
\text { 5) Facilidade de } \\
\text { movimentos; } \\
\text { 6) Conforto e } \\
\text { Segurança; } \\
\text { 7) Capacidade de } \\
\text { guardar coisas. }\end{array}$ \\
\hline $\begin{array}{l}\text { Qualidade } \\
\text { Estética }\end{array}$ & $\begin{array}{l}\text { 1) Combinação de } \\
\text { Formas, Cores, } \\
\text { Texturas e Materiais; } \\
\text { 2) Acabamentos; } \\
\text { 3) Movimentos. }\end{array}$ & $\begin{array}{l}\text { 1) Combinação de } \\
\text { Formas, Cores, } \\
\text { Texturas e Materiais; } \\
\text { 2) Acabamentos; } \\
\text { 3) Movimentos } \\
\text { (caimento da peça) } \\
\text { 4) Recortes } \\
\text { 5) Volumes. }\end{array}$ \\
\hline
\end{tabular}

Tabela 3: Categorias do Método Aplicável ao Vestuário Fonte: ROSA (2011, p. 84).

Assim, com base nas Categorias do Método Aplicável ao Vestuário, Rosa (2011) estabeleceu os Parâmetros para Confecção a partir dos requisitos ergonômicos propostos pelo método.

Portanto, o primeiro critério, Facilidade de Manuseio, refere-se à facilidade para entender e mover ou mexer os componentes do vestuário.

Adaptação Antropométrica seria adaptar as medidas do vestuário conforme as tabelas padronizadas pela ABNT (2015).

Fornecimento claro de Informações envolve a especificação de instruções quanto ao uso e manutenção do produto.

Facilidade para vestir e despir são as qualidades que o produto apresenta de modo que facilite essa tarefa pelo usuário.

Facilidade de movimentos é a confecção do vestuário com folgas e elementos que permitam a livre movimentação pelo usuário durante as tarefas executadas.

Conforto envolve a comodidade e bem-estar físico e sensorial por meio de cores, materiais, formas e acabamentos que possibilitem o conforto tátil, estático e dinâmico durante a utilização da peça.

Segurança é a capacidade que o vestuário tem de proteger contra eventuais riscos, danos e perigos, por meio de aviamentos, costuras, tecidos e outros componentes da peça.
Por fim, a Capacidade de guardar coisas refere-se à possibilidade de armazenamento de itens pelo usuário, como por exemplo, a utilização de bolsos.

Assim, com base nesses Parâmetros para Confecção de Rosa (2011) e na norma regulamentadora NBR 16365:2015, foram desenvolvidos requisitos ergonômicos para o vestuário infantil de crianças menores, que compreende o período até os sete anos de idade.

\section{Resultados e Discussões}

A criança, conforme o seu crescimento, tende a apresentar uma relação diferenciada com a roupa, conforme o período de desenvolvimento no qual se encontra. Diante disso, é preciso pensar em todos os fatores que influenciam essa relação e nos usuários que estão envolvidos nesse processo.

No momento da Primeira Infância, os pais representam papel fundamental na função de escolher o vestuário e vestir a criança. Com isso, é preciso pensar na roupa de modo que contemple requisitos ergonômicos, mas que também envolva a facilidade de vestir e manutenção das peças. Assim, as roupas devem ter praticidade, conforto e segurança, além de articular fatores estéticos com os ergonômicos.

As tabelas abaixo (tabelas 4,5 e 6) representam os requisitos ergonômicos necessários ao vestuário infantil, contemplando o período do nascimento até os sete anos de idade.

\begin{tabular}{|l|l|}
\hline $\begin{array}{l}\text { Requisitos } \\
\text { Ergonômicos }\end{array}$ & \multicolumn{1}{|c|}{ Primeira infância } \\
\cline { 2 - 2 } $\begin{array}{l}\text { Facilidade de } \\
\text { manuseio }\end{array}$ & $\begin{array}{l}\text { Utilização de elástico na cintura, aviamentos } \\
\text { de qualidade e botões de pressão fáceis de } \\
\text { abrir e fechar. }\end{array}$ \\
\hline $\begin{array}{l}\text { Adaptação } \\
\text { antropométri } \\
\text { ca }\end{array}$ & $\begin{array}{l}\text { Medidas conforme os padrões da NBR } \\
15800 .\end{array}$ \\
\hline $\begin{array}{l}\text { Fornecimento } \\
\text { claro de } \\
\text { informações }\end{array}$ & $\begin{array}{l}\text { Informações disponíveis na etiqueta da peça } \\
\text { que informem sobre processos de lavagem } \\
\text { e conservação. }\end{array}$ \\
\hline $\begin{array}{l}\text { Facilidade } \\
\text { para despir e } \\
\text { vestir }\end{array}$ & $\begin{array}{l}\text { Abertura na região do gancho. Exemplo: } \\
\text { abertura no tip-top para troca de fraldas. } \\
\text { Desenvolvimento de peças versáteis, 2 em 1 } \\
\text { (calça com pé) e 3 em 1 (tip-top). }\end{array}$ \\
\hline $\begin{array}{l}\text { Facilidade de } \\
\text { movimentos }\end{array}$ & $\begin{array}{l}\text { Folgas na modelagem para movimentação e } \\
\text { acondicionamento da fralda. } \\
\text { Resistência à tração e alongamento. }\end{array}$ \\
\hline Conforto & Conforto térmico e tátil na confecção das \\
\hline
\end{tabular}




\begin{tabular}{|l|l|}
\hline & $\begin{array}{l}\text { roupas. } \\
\text { Utilização de tecidos macios que não } \\
\text { agridam a pele do bebê. }\end{array}$ \\
\hline Segurança & $\begin{array}{l}\text { Atentar para substâncias nocivas; } \\
\text { Aviamentos devem ser compostos por } \\
\text { elementos que não sejam nocivos à saúde } \\
\text { do bebê e resistentes ao arrancamento. } \\
\text { Tecidos não podem ser inflamáveis. } \\
\text { Ph do tecido deve estar em equilíbrio com o o } \\
\text { ph da pele do bebê. } \\
\text { Os bordados devem ter forro interno. } \\
\text { Evitar costuras grossas, partes } \\
\text { protuberantes e etiquetas costuradas com } \\
\text { fios de poliamida para não agredir a pele. }\end{array}$ \\
\hline $\begin{array}{l}\text { Capacidade } \\
\text { de guardar } \\
\text { coisas }\end{array}$ & Não se aplica \\
\hline
\end{tabular}

Tabela 4: Requisitos Ergonômicos para a primeira infância.

Fonte: Os autores (2016).

No período Pré-Escolar, por sua vez, a capacidade cognitiva da criança encontra-se em evidência, e nessa fase é interessante pensar também nos fatores de atração e identificação da criança com o vestuário, como por exemplo, a utilização de personagens na estamparia.

Nessa fase, observa-se também a introdução de peças do vestuário adulto, como calças jeans. $\mathrm{E}$ assim, é preciso atentar para os critérios ergonômicos, no sentido de escolher os tecidos, aviamentos e costuras que contemplem a segurança e bem-estar da criança durante sua utilização.

Com isso, tecidos com beneficiamentos podem ser utilizados para garantir a maciez nas peças, além da introdução de características lúdicas ao vestuário, que estimulem o desenvolvimento cognitivo da criança.

\begin{tabular}{|l|l|l|}
\hline \multirow{2}{*}{$\begin{array}{l}\text { Requisitos } \\
\text { Ergonômicos }\end{array}$} & \multicolumn{2}{|l|}{ Período pré - escolar } \\
\cline { 2 - 3 } $\begin{array}{l}\text { Facilidade de } \\
\text { manuseio }\end{array}$ & $\begin{array}{l}\text { Utilização de aviamentos de qualidade, } \\
\text { zíper fácil de correr, botões fáceis de abrir } \\
\text { e fechar. }\end{array}$ \\
\hline \multirow{2}{*}{$\begin{array}{l}\text { Adaptação } \\
\text { antropométrica }\end{array}$} & $\begin{array}{l}\text { Medidas conforme } \\
\text { os padrões da } \\
\text { NBR 15800. } \\
\text { Blusas sem } \\
\text { abertura devem ter } \\
\text { o decote } \\
\text { proporcional à } \\
\text { cabeça do bebê } \\
\text { que é maior em } \\
\text { relação ao corpo. }\end{array}$ & $\begin{array}{l}\text { Medidas conforme } \\
\text { os padrões da } \\
\text { NBR 15800. }\end{array}$ \\
\hline $\begin{array}{l}\text { Fornecimento } \\
\text { claro de }\end{array}$ & $\begin{array}{l}\text { Informações disponíveis na etiqueta da } \\
\text { peça que informem sobre processos de }\end{array}$ \\
\hline
\end{tabular}

\begin{tabular}{|c|c|c|}
\hline informações & \multicolumn{2}{|c|}{ lavagem e conservação. } \\
\hline $\begin{array}{l}\text { Facilidade para } \\
\text { despir e vestir }\end{array}$ & \multicolumn{2}{|c|}{$\begin{array}{l}\text { Aberturas em locais usuais e de fácil } \\
\text { acesso pela criança. }\end{array}$} \\
\hline $\begin{array}{l}\text { Facilidade de } \\
\text { movimentos }\end{array}$ & \multicolumn{2}{|c|}{$\begin{array}{l}\text { Folgas na modelagem para } \\
\text { movimentação. } \\
\text { Resistência à tração e alongamento. }\end{array}$} \\
\hline Conforto & \multicolumn{2}{|c|}{$\begin{array}{l}\text { Conforto térmico e tátil na confecção das } \\
\text { roupas. Utilização de tecidos macios que } \\
\text { não agridam a pele. } \\
\text { Conforto sensorial: inclusão de estampas } \\
\text { de personagens. }\end{array}$} \\
\hline Segurança & $\begin{array}{l}\text { Cordões devem } \\
\text { ser evitados, seja } \\
\text { no pescoço, } \\
\text { cintura, fixos e } \\
\text { deslizantes. } \\
\text { Evitar costuras } \\
\text { grossas, partes } \\
\text { protuberantes e } \\
\text { etiquetas } \\
\text { costuradas com } \\
\text { fios de poliamida } \\
\text { para não agredir a } \\
\text { pele. } \\
\text { Atentar para } \\
\text { substâncias } \\
\text { nocivas; } \\
\text { Tecidos não } \\
\text { podem ser } \\
\text { inflamáveis. } \\
\text { Evitar botões } \\
\text { metálicos para não } \\
\text { ocasionar } \\
\text { queimaduras, } \\
\text { preferir botões } \\
\text { plásticos. }\end{array}$ & $\begin{array}{l}\text { Faixas e cordões } \\
\text { depois de } \\
\text { amarrados não } \\
\text { podem passar do } \\
\text { limite da roupa em } \\
\text { comprimento. } \\
\text { Evitar costuras } \\
\text { grossas, partes } \\
\text { protuberantes e } \\
\text { etiquetas } \\
\text { costuradas com } \\
\text { fios de poliamida } \\
\text { para não agredir a } \\
\text { pele. } \\
\text { Atentar para } \\
\text { substâncias } \\
\text { nocivas; } \\
\text { Tecidos não } \\
\text { podem ser } \\
\text { inflamáveis. }\end{array}$ \\
\hline $\begin{array}{l}\text { Capacidade de } \\
\text { guardar coisas }\end{array}$ & Não se aplica. & Bolsos utilitários. \\
\hline
\end{tabular}

Tabela 5: Requisitos Ergonômicos para o período préescolar.

Fonte: Os autores (2016).

No período da Segunda Infância, a criança apresenta um estágio de desenvolvimento físico, cognitivo e motor avançado, além de possuir habilidades para atividades diferenciadas.

O vestuário, desse modo, deve apresentar critérios ergonômicos compatíveis com o período, pensando na experiência do usuário durante sua utilização, pois nessa fase a criança já analisa outros fatores além dos estéticos na escolha da roupa. Assim, quesitos simbólicos como a marca são evidenciados, e fatores de identificação como cores e escolha de personagens continuam.

Além disso, preferências com relação ao estilo da roupa se intensificam, uma vez que a criança está 
construindo suas preferências e identidade.

\begin{tabular}{|l|l|}
\hline $\begin{array}{l}\text { Requisitos } \\
\text { Ergonômicos }\end{array}$ & Segunda Infância \\
\cline { 2 - 2 } $\begin{array}{l}\text { Facilidade de } \\
\text { manuseio }\end{array}$ & $\begin{array}{l}\text { Utilização de aviamentos de qualidade, } \\
\text { zíper fácil de correr, botões fáceis de } \\
\text { abrir e fechar. }\end{array}$ \\
\hline $\begin{array}{l}\text { Adaptação } \\
\text { antropométrica }\end{array}$ & $\begin{array}{l}\text { Medidas conforme os padrões da NBR } \\
15800 .\end{array}$ \\
\hline $\begin{array}{l}\text { Fornecimento } \\
\text { claro de } \\
\text { informações }\end{array}$ & $\begin{array}{l}\text { Informações disponíveis na etiqueta da } \\
\text { peça que informem sobre processos de } \\
\text { lavagem e conservação. }\end{array}$ \\
\hline $\begin{array}{l}\text { Facilidade para } \\
\text { despir e vestir }\end{array}$ & $\begin{array}{l}\text { Aberturas em locais usuais e de fácil } \\
\text { acesso pela criança. }\end{array}$ \\
\hline $\begin{array}{l}\text { Facilidade de } \\
\text { movimentos }\end{array}$ & $\begin{array}{l}\text { Folgas na modelagem para } \\
\text { movimentação. } \\
\text { Resistência à tração e alongamento. }\end{array}$ \\
\hline Tabela 6: Requisitos Ergonômicos para a segunda \\
infância até os sete anos.
\end{tabular}

Desse modo, durante o desenvolvimento da criança observa-se a evolução da sua interação com o vestuário, que inicialmente é mais passivo, comandado pelos pais, para uma postura mais ativa, de identificação de sua personalidade e preferências por meio de suas escolhas.

\section{Conclusão}

O artigo buscou apresentar requisitos ergonômicos necessários ao desenvolvimento do vestuário infantil, de modo que os fatores concernentes à criança e seus responsáveis sejam aferidos durante o planejamento do produto.

Assim, deve-se pensar na interação da criança com a roupa para cada fase de seu desenvolvimento, e atentar para os quesitos de segurança em conjunto com atributos de praticidade e estética, respeitando os critérios ergonômicos.

Para isso, deve-se realizar processos de controle de qualidade junto ao produto, para que ocorra uma padronização e minimização dos riscos ao cliente.

Além disso, é importante também realizar pesquisas de mercado junto ao público a fim de identificar os perigos, necessidades, e oportunidades relatadas pelos responsáveis da criança, e verificar quais são suas dificuldades e sugestões com relação ao vestuário infantil.

Por fim, deve-se estar atento ao lançamento de novas tecnologias que possam auxiliar nesse processo, e à publicação de atualizações em normas regulamentadoras do setor.

\section{Referências}

\section{ASSOCIAÇÃO BRASILEIRA DE NORMAS}

TÉCNICAS. NBR 16365: Segurança de roupas infantis - Especificações de cordões fixos e cordões ajustáveis em roupas infantis e aviamentos em geral - Riscos físicos. Rio de Janeiro: 2015. Disponível em:

$<$ http://www.abntcatalogo.com.br/sebrae/java/vwnor ma.aspx?Q=9B6D6788D0B06DB41EFB105980AA 0CF106E35D843FB5B171BCBF98AAC26CF201> Acesso em: 07 jul. 2016.

FARIA, Anália. Desenvolvimento da criança e adolescente segundo Piaget. São Paulo: Editora Ática, 2001.

FORTKAMP, Eloisa; RAUPP, Marilene. Características evolutivas do desenvolvimento infantil: zero a seis anos. Florianópolis: Ed. Dos autores, 1989.

\section{MANNING, Sidney. O desenvolvimento da criança e do adolescente. São Paulo: Editora Cultrix, 1977.}

MARTINS, Suzana B. O conforto no vestuário: uma interpretação da ergonomia - metodologia para avaliação de usabilidade e conforto no vestuário. 
Florianópolis: UFSC, Departamento de Engenharia de Produção, 2005. Tese de Doutorado.

MUSSEN, Paul; CONGER, John; KAGAN, Jerome. Desenvolvimento e personalidade da criança. 4. Ed. São Paulo: Editora Harper e Row do Brasil LTDA, 1977.

PEZZOLO, Dinah B. Tecidos: história, tramas, tipos e usos. $3^{\text {a }}$. Edição. São Paulo: Editora Senac São Paulo, 2007.

ROSA, Arlete P. da. A importância da etiqueta no produto têxtil. São José: Editora e Gráfica Odorizzi Ltda., 2002.

ROSA, Lucas da. Vestuário industrializado: uso da ergonomia nas fases de gerência de produto, criação, modelagem e prototipagem, 2011. $176 \mathrm{f}$. Tese (Doutorado) - Curso de Design, Pontifícia Universidade Católica do Rio de Janeiro, Rio de Janeiro, 2011. Cap. 3. Disponível em: HTTP://www.maxwell.vrac.pucrio.br/18873/18873 1.PDF Acesso em: 06 jul. 2016.

SEBRAE/SIS - Sistema de Inteligência Setorial. Segurança no vestuário infantil. Vestuário Boletim de Tendências, 2014. Disponível em: < https://sis.sebrae-sc.com.br/produtos/boletins-detendencia/seguranca-no-vestuarioinfantil/54c6815bf17388e7058b4b70> Acesso em: 08 set. 2016.

TREPTOW, Doris. Inventando moda: planejamento de coleção. Brusque: D. Treptow, 2003.

VIGOTSKII, L.S; LURIA, A.R; LEONTIEV, A.N. Linguagem, desenvolvimento e aprendizagem. São Paulo: Editora da Universidade de São Paulo, 1988.

VOIGT, Priscila. Comportamento do consumidor infantil: características e decisões de compra. Florianópolis, 2007. 487 f. Dissertação (Mestrado Profissional em Administração). Programa de PósGraduação em Administração. Universidade do Estado de Santa Catarina, Florianópolis, 2007.
Agradecimento a CAPES, CNPq, aos professores e coordenação do curso de Pós-Graduação em Design da UDESC.

\section{Agradecimentos}

